\title{
Third molar extractions: a retrospective study of 1178 cases
}

\author{
Exodontias de terceiros molares: estudo retrospectivo de 1178 casos
}

\author{
Fued Samir SALMEN ${ }^{1}$ \\ Marina Reis OLIVEIRA' \\ Marisa Aparecida Cabrini GABRIELLI ${ }^{1}$ \\ Ana Cláudia Gabrielli PIVETA ${ }^{1}$ \\ Valfrido Antonio PEREIRA-FILHO' \\ Mario Francisco Real GABRIELLI'
}

\section{ABSTRACT}

\section{Objective}

This study aims to investigate the demographics, patient health status, position of the teeth, pericoronitis incidence, surgical complications, use of antibiotics to third molar removal and correlate those findings.

\section{Methods}

Based on panoramic radiographs, the teeth were classified as proposed by Pell and Gregory and Winter. The binomial test for proportions with a significance level of $5 \%$ was applied.

\section{Results}

Records of 337 patients submitted 1178 third molar extractions in the period from 1993 to 2011 were reviewed. Most upper teeth were vertically positioned, $(84.2 \%)(p<0.0001)$, class I $(49.55 \%)(p<0.0001)$, position C $(58.88 \%)(p<0.0001)$ and most inferiors were mesioangulated $(42.03 \%)(p<0.0122)$, class II $(60.22 \%)(p<0.0001)$, position $A(48.15 \%)(p<0.0001)$. Complications occurred in $2.88 \%$ of the procedures $(p<0.0006)$, mainly in women $(69.7 \%)(p<0.0014)$ and more frequently in patients who did not receive antibiotics $(71.43 \%)(p<0.0027)$. Complications were more frequent after extraction of inferior third molars $(75.75 \%)(p<0.0001)$. The most common complication was alveolitis $(52.51 \%)(p<0.0006)$.

\section{Conclusion}

In this study, the complication rates were low. They were more frequent in women who did not receive antibiotics. The most common complication was alveolitis.

Indexing terms: Impacted tooth. Tooth extraction. Third molar.

\section{RESUMO}

\section{Objetivo}

Este estudo objetivou descrever os dados demográficos dos pacientes, posicionamento dos terceiros molares, complicações cirúrgicas, condição sistêmica, histórico de pericoronarite e antibioticoterapia e correlacionar esses achados.

\section{Métodos}

Com base em radiografias panorâmicas os dentes foram classificados conforme proposto por Pell e Gregory e Winter. Foi utilizado o teste Binomial para proporções a 5\% de significância.

\section{Resultados}

Foram revisados os prontuários de 337 pacientes submetidos a 1178 exodontias durante o perído de 1993 a 2011 . Os dentes superiores apresentaram-se predominantemente verticais $(84,2 \%)(p<0,0001)$, classe I $(49,55 \%)(p<0,0001)$, posição C $(58,88 \%)(p<0,0001)$ e os inferiores mesioangulados $(42,03 \%)(p<0,0122)$, classe II $(60,22 \%)(p<0,0001)$, posição $A(48,15 \%)(p<0,0001)$. As complicações ocorreram em apenas $2,88 \%$ das cirurgias, foram mais comuns em mulheres $(69,7 \%)$ ( $p<0,0014)$ e em pacientes que não fizeram uso de antibióticos $(71,43 \%)(p<0,0027)$. A maioria das complicações ocorreu após extrações de dentes inferiores $(75,75 \%)(p<0,0001)$. A complicação mais comum foi a alveolite $(52.51 \%)(p<0.0006)$.

\section{Conclusão}

Neste estudo, as complicações não foram frequentes e acometeram mais mulheres e pacientes que não fizeram uso de antibióticos, sendo a alveolite a mais comumente observada.

Termos de indexação: Dente Impactado; Extração Dentária; Terceiro Molar.

\footnotetext{
${ }^{1}$ Universidade Estadual Paulista Júlio de Mesquito Filho, Faculdade de Odontologia. Rua Humaitá, 1680, Centro, 14801-903, Araraquara, SP, Brasil Correspondência para / Correspondence to: FS SALMEN. Email: <drfued@icloud.com>.
} 


\section{INTRODUCTION}

One of the most common dental procedures in patients aged 16 to 21 years is the extraction of third molars ${ }^{1}$. The most frequent undesirable ocurrences in such procedures are pain, edema, dysphagia and infection ${ }^{2-3}$. This creates controversy about prophylactic removal of third molars. The most frequent arguments for removal are recurrent pericoronitis, unfavorable eruption trajectory and prevention of tooth crowding, periodontal compromise and development of pathology $y^{4-5}$.

It is not easy to establish the difficulty level in third molar extraction. Several auxiliary methods have been proposed but none is totally reliable ${ }^{2}$. The estimate of the degree of difficulty has to be made preoperatively and depends upon tooth position, morphology and number of roots, among others ${ }^{6-7}$.

Most classification methods for third molars are based on radiographic imaging. Pell and Gregory's classification ${ }^{8}$ is still a widely used method for estimation of extraction difficulty and takes into account the relation of the tooth with the occlusal plane and mandibular ramus ${ }^{9}$. Winter's classification ${ }^{10}$ can be used as a complement because it considers the angulation of the third molar8. The correct classification is important because it aids the clinician in the perioperative decision process, preoperative preparation and prescription. This can reduce morbidity and risk of complications and define the necessity or not of sending the patient to specialized care ${ }^{6-7,11}$. This article reviews a significant number of third molar extractions and related complications.

\section{METHODS}

This study was approved by the ethics committee of the institution where it was developed. Records of 337 patients submitted to removal of 1178 third molars in the period from 1993 to 2011 were reviewed. Data including demographics, health status, previous history of pericoronitis, use of pre and postoperative antibiotics and complications were verified. All patients who had at least one third molar extracted were included, with exception of those who had incomplete records.

The third molars were classified using radiographic panoramic images according to the degree of impaction and space avaliable for eruption as proposed by Pell \& Gregory8. Winter's classification 10 was also used to describe the angulation in relation to the long axis of the second molar.

All extractions were performed by one experienced surgeon, who also applied the classifications based on panoramic radiographs. Previously, an intraexaminer calibration was done by triplicate evaluations using random radiographs of patients not included in the study. Calibration is considered acceptable if agreement is higher than $80 \%$. All surgical procedures were performed under local anesthesia.

The data were organized in a Microsoft Excel table and submitted to the binomial test for proportions at the significance level of $5 \%$ (Biostat software 5.0).

This research was conducted according with the Helsink Declaration (2000) and with standard of resolution 466/12 of Nacional Health Council and the experimental protocol was submitted and approved for Ethical Committee under protocol number 1.048.869/2015.

\section{RESULTS}

In the studied population, 229 patients were women $(60.74 \%)$ e 148 were men (39.26\%). The number of female patients was significantly higher than males $(p<0.0001)$ and mean age was 22.62 years (SD 8.22).

Most teeth were extracted in the lower arch, corresponding to 621 third molars (52.7\%) and 557 $(47.3 \%)$ were extracted in the upper arch. This difference was statistically significant $(p<0.0084)$. According to the Winter's classification (1926)10, 469 upper third molars were vertically positioned (84.2\%), 42 were mesioangulated (7.54\%), 40 were distoangulated (7.18\%) and only three were bucally angulated (0.54\%). The number of vertically positioned teeth was significantly higher $(p<0.0001)$.

The number of mesio and distoangulated teeth was statistically greater than the number of horizontal and buccally angulated teeth. $(p<0.0001)$.

Concerning Pell and Gregory's classification8, 276 upper third molars were categorized as Class I $(49.55 \%), 194$ were Class II (34.83\%) and 87 were Class III (15.62\%). The percentage of class I teeth was significantly higher than Class II or III $(p<0.0001)$. The percentage of Class II teeth was significantly greater than class III $(p<0.0001)$. According to the depth of impaction, 158 upper third molars were categorized as A (28.37\%), 71 as $B(12.75 \%)$ and 328 as C (58.88\%). The percentage 
of $C$ type was higher than $A$ and $B(p<0.0001)$. A was higher than $B(p<0.0001)$.

According to the Winter's classification10, from 621 lower third molars, 261 (42.03\%) were mesioangulated, 218 were positioned vertically (35.1\%), 114 were horizontal (18.36\%), 17 distoangulated (2.74\%), 10 buccally angulated (1.61\%) and 1 lingually angulated $(0.16 \%)$. The percentage of mesioangulated teeth was statistically greater than vertical teeth $(p<0.0122)$ and all other angulations $(p<0.0001)$.

According to Pell \& Gregory's classification ${ }^{8}, 166$ lower third molars were categorized as Class I (26.73\%), 374 as Class II (60.22\%) and 81 as classe III (13.05\%). The percentage of Class II teeth was significanty greater than Class I and III $(p<0.0001)$ and Class I percentage was higher than Class III $(p<0.0001)$. In relation to the depth of impaction 299 teeth were classified as A (48.15\%), 193 as B (31.08\%) e 129 as C (20.77\%). The percentages were significantly different, in the decreasing order $A>B>C(p<0.0001)$.

Regarding preoperative infection, from the 1178 extracted teeth, 1129 were asymptomatic (95.84\%) and 49 presented with pericoronitis $(4.16 \%)$, which is statistically lower $(p<0.0001)$.

All patients in the studied population were classified as ASA I or II. 288 had no known significant systemic alterations (76.40\%), while 89 presented some light and controlled systemic alteration or were smokers $(23.60 \%)$. The percentage of healthy patients was significantly higher $(p<0.0001)$. Among those 89 patients, 50 referred drug allergy $(56.18 \%), 9$ were smokers $(10.11 \%), 7$ presented gastritis $(7.87 \%), 4$ had depression (4.5\%). Hypothyroidism (4.5\%) and bronchitis $(4.5 \%)$ were referred by 4 epileptic $(2.24 \%)$ and two were asthmatic (2.24\%). One patient was patients, 2 were anemic $(1.12 \%), 1$ presented rheumatologic disease $(1.12 \%)$ and one had Down's syndrome (1.12\%).

Drug allergy was the most common systemic condition encountered $(p<0.0001)$. Fourteen patients were allergic to penicillin, 9 to acetylsalicylic acid (18\%), 9 to dipyrone (18\%), 6 to thimerosal (12\%), 4 to iodine $(8 \%), 3$ to sulphonamide $(6 \%), 2$ to nonsteroidal antinflammatories (NSAIDS) (4\%), 1 to dexamethasone $(2 \%), \quad 1$ to acetaminophen (2\%) and 1 to rifampicin $(2 \%)$. The percentage of patients with allergy to penicillin was not statistically higher than that for patients allergic to acetylsalicylic acid or dipyrone $(p<0.2348)$, although it was statistically higher than for the other drug allergies.
Complications occurred in 33 records (2.88\%). Thus, the percentage of procedures without any complication was statistically higher $(p<0.0001)$. The most commmon complication was alveolitis, which occurred in 17 sockets $(51.52 \%)(p<0.0006)$. Other complications were 4 occurrences of root fracture $(12.12 \%), 4$ cases of abscess $(12.12 \%)$, excessive bleeding in 3 cases $(9.09 \%)$, 3 oroantral communications $(9.09 \%)$, penetration of 1 root into the maxillary sinus (3.03\%) and hypoesthesia in one case (3.03\%). Complications are shown in Figure 1.

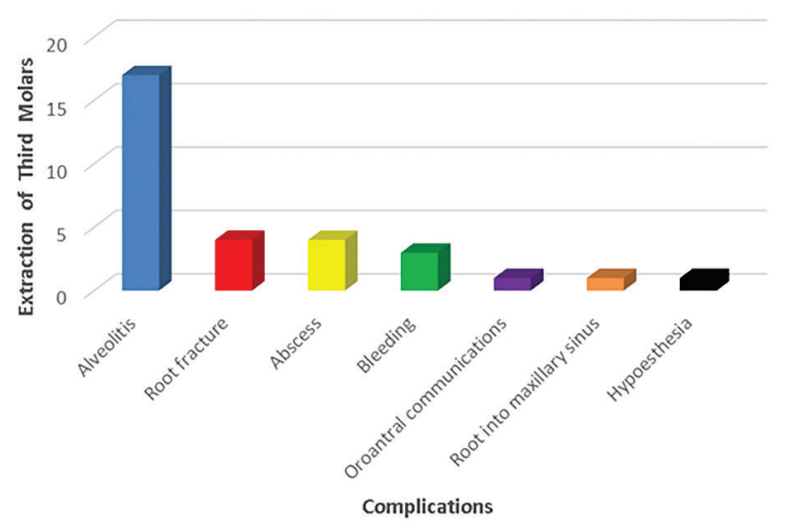

Figure 1. Graphic of the complications after third molar removal.

Twenty-three of the complications occurred in women $(69.7 \%)$ which was significantly higher than in men, who developed complications in 10 cases (30.3\%) $(p<0.0014)$. Considering only the 21 cases of inflammatory and infectious complications, which ocurred in $1.27 \%$ of the extractions, 15 happened in women $(71.43 \%)$ and 6 in men $(28.57 \%)$. The number of such complications was significantly higher in women $(p<0.0055)$. In only 5 cases $(23.81 \%)$ the involved tooth presented preoperative pericoronitis. The percentage of inflammatory and infectious complications was statistically higher in asymptomatic teeth $(p<0.0007)$. 15 patients $(71.43 \%)$ who did not receive antibiotics and $6(28.57 \%)$ who were in use of antibiotics developed that kind of complication and this was statistically significant $(p<0.0027)$.

In the studied population smoking was not related to a greater number of complications, which occurred in two patients with a smoking habit (6.06\%), while 31 cases $(93.94 \%)$ ocurred in non-smoking patients. This was statistically significant $(p<0.0001)$. Complications were observed in 20 patients under 25 years old (60.6\%) and in 13 patients over that age (39.4\%), which was not statistically significant $(p<0.0848)$. 
The majority of complications were found after lower third molar extractions, ocurring in 25 cases (75.75\%), while $8(24.25 \%)$ were related to upper teeth, which was statistically significant $(p<0,0001)$. Considering Winter's classification 10, nine mesioangulated teeth $(27.27 \%), 9$ vertical $(27.27 \%), 8$ horizontal $(24.25 \%), 4$ distoangulated $(12.12 \%), 2$ bucally angulated (6.06\%) and 1 lingually angulated tooth (3.03\%) presented complications. There was no statistically significant difference in the number of complications between mesioangulated and vertically positioned teeth $(p<1.0)$ or to horizontal $(p<0.7783)$ and distoangulated teeth $(p<0.1216)$. It was higher than the complication rate for buccally $(p<0.0208)$ and lingually angulated teeth $(p<0,006)$. Figure 2 shows complications in relation to tooth position.

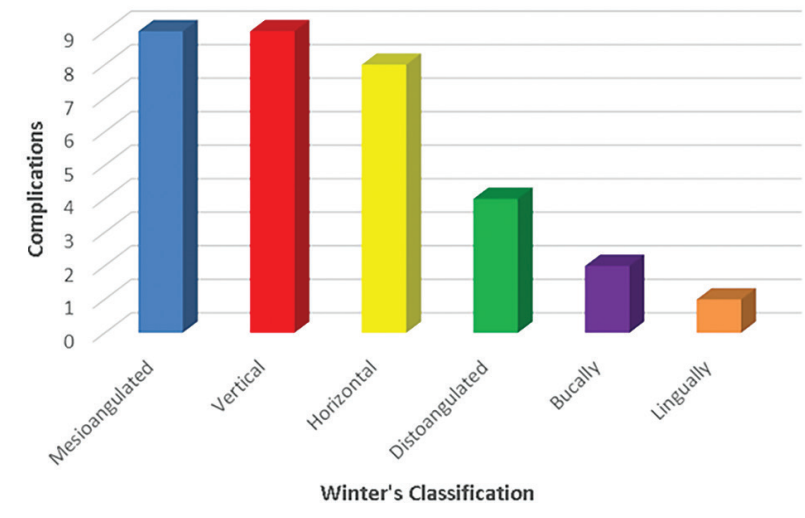

Figure 2. Graphic of the complications in relation to tooth position.

Considering Pell e Gregory's classification ${ }^{8}$, most complications (18) were observed in Class II third molars (54.55\%), followed by 10 cases in Class I (30.30\%) and 5 cases in Class III (15.15\%). The percentage of complications in Class II was significantly higher than in Class I $(p<0.0463)$ and Class III $(p<0.0008)$. Figure 3 shows complications in relation to depth of impaction.

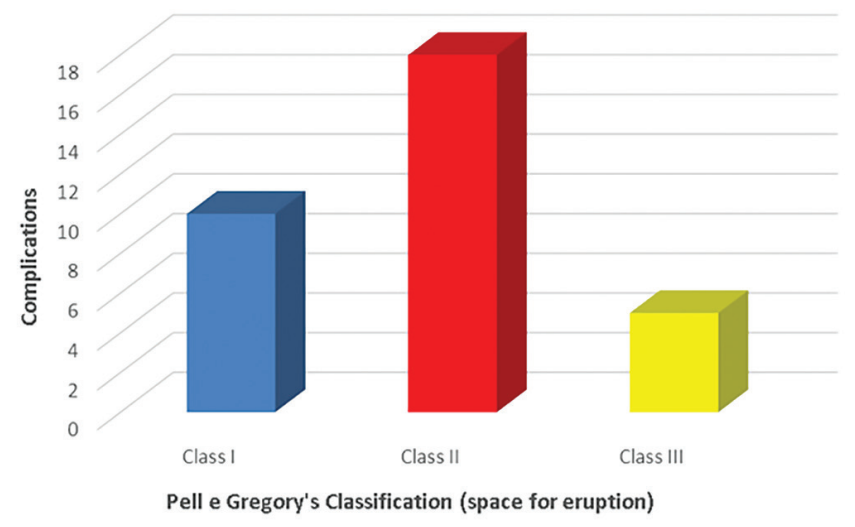

Figure 3. Graphic of the complications in relation to space for eruption.
Regarding the depth of impaction of the third molars that presented complications, 14 cases were categorized as position A (42.43\%), 13 were C (39.39\%) and 6 were B (18.18\%). Percentage of complications was statistically higher for category $A$ in comparison with category $B(p<0.0321)$. There was no significant difference between $A$ and $C(p<0.8023)$ or between $B$ and $C$ $(p<0.0570)$. Figure 4 shows complications related to depth of impaction.

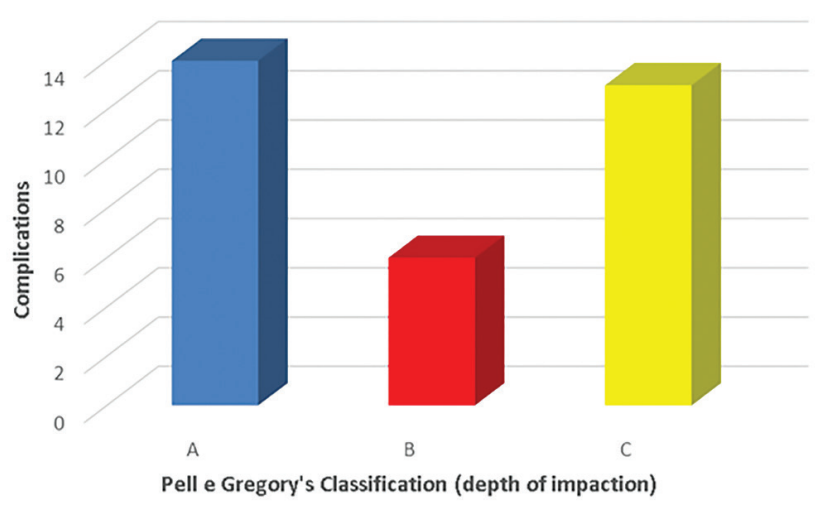

Figure 4. Graphic of the complications in relation to tooth position.

\section{DISCUSSION}

Decision about removal or maintenance of those teeth usually occur towards the end of adolescence and beginning of adult life. Thus, 95\% of third molar extractions occur between 16 and 21 years of age'. In the studied sample mean age agrees to other studies. Santos et al. ${ }^{12}$ found a mean age of 22.46 anos in 80 patients. In the same study, most patients were male $(67.5 \%)^{12}$. As in the present study, Morales-Trejo et al. ${ }^{11}$ had a greater number of female patients for third molar removal (65.3\%).

Regarding the difficulty of removal, the literature is highly divergent. Several methods were proposed to estimate extraction complexity. Winter ${ }^{10}$ and Pell and Gregory ${ }^{8}$ classifications are widely known. In this study the vertical position was the most common for the upper third molars. This differs from the results from Morales-Trejo et al. ${ }^{11}$ and is in agreement to Hupp et al. ${ }^{13}$ who found the vertical impaction to be the most frequent, followed by the distoangulated and mesioangulated. The remaining positions are seldom found in maxillary teeth, corresponding to less than $1 \%$ of the upper third molars ${ }^{13}$. Regarding the depth of impaction, most upper third molars presented deep impaction (position C). However, Morales-Trejo et al. ${ }^{11}$ 
describe upper third molars mainly in position A, not deeply impacted, but the sample studied was much samaller.

In the present population, regarding Winter's classification $^{10}$, the most common position was mesioangulation, which agrees with the results of MoralesTrejo et al. ${ }^{11}$ and Hupp et al. ${ }^{13}$. In relation to Pell and Gregory's classification $^{8}$ concerning eruption space, most teeth were categorized as Class II. Other studies show a greater percentage of class I teeth ${ }^{11,14}$. The most common depth of impaction in the lower molars was position A, as previously described Morales-Trejo et al. ${ }^{11}$.

Complications were more frequent in lower third molar extractions as previously described by Bui et al. ${ }^{15}$. Freudlsperger et al. ${ }^{6}$ measured the surgical complexity of third molar extraction and found a high correlation between the increase in surgical difficulty and higher incidence of inflammatory postoperative complications. In the present sample, however, most complications occurred after extraction of mesioangulated or vertically positioned teeth and class II, considered of minimal or moderate difficulty for removal ${ }^{13}$. In addition, most complications developed in teeth little or not impacted (position A) or in deep bone impaction (position C). Arteagoitia et al. ${ }^{16}$, also observed more complications in deeply impacted teeth.

Besides the position of the tooth, other factors are associated to the difficulty of extraction and complications, such as age, sex, chronic use of medication, antibiotics, smoking, experience of the surgeon, among others ${ }^{12,16}$. Adult patients present an increase in bone density, which can lead to a more traumatic procedure and higher risk of complications ${ }^{6,15}$. According to Pogre ${ }^{17}$ the removal of third molars after 25 years of age can be more difficult with higher risk of complications. In the studied sample, age was not related to the occurrence of complications. This fact is a controversial issue in the literature. Several studies associated increase in age to extraction difficulty and higher complication rates ${ }^{3,9,16,18}$. Other studies did not find any increase in morbidity or complication rate in patients over 25 years of age ${ }^{19}$.

Complications were more frequent in women. Smoking did not increase the incidence of complications in the studied sample. Bui et al. ${ }^{15}$ found no significant association between gender and smoking to increased risk of complications after third molar extraction. The global rate of complications after third molar extraction varies from 4.615 to $21 \%{ }^{20}$. It was $2.88 \%$ in this sample, the most common complication being alveolitis, as previously described ${ }^{4}$. Inflammatory and infectious complicatons developed after $1.27 \%$ of the extractions. Freudlsperger et al. ${ }^{6}$ observed an incidence of inflammatory complications of $22.1 \%$ after 585 extractions of lower third molars.

Although there is controversy about the use of antibiotics after third molar removal, in the present population the incidence of complications was statistically higher in patients who did not receive pre and/or postoperative antibiotics. The meta-analysis from Ren and Malmstrom ${ }^{21}$ showed that the use of antibiotics may reduce the incidence of alveolitis and postoperative infections. Arteagoitia et al. ${ }^{16}$ also showed that the administration of amoxicillin associated with clavulanic acid for 4 days postoperatively reduced inflammatory and infectious complications. Controversially, Poeschl et al. ${ }^{22}$ found no benefit between the use of amoxicillin and clavulanidc acid or clindamycin on the healing process or prevention of postoperative complications.

In general, systemic disease can increase the incidence of complications ${ }^{15,23-24}$. On the context of postoperative infection, another factor to be considered is the presence of preoperative infection ${ }^{23}$. In the studied sample, in only $23.81 \%$ of the extractions resulting in inflammatory or infectious complications and there was a previous history of pericoronitis.

\section{CONCLUSION}

In the studied sample, few complications occurred and there were more frequent in mesioangulated or verticalized teeth, Class II, position A and C. The Incidence of complications was not influenced by age or smoking, but it was higher in women and in patients who did not receive antibiotics.

\section{Acknowledgements}

We thank the Diagnosis \& Surgery Department, Araraquara Dental School, São Paulo State University FOAr/UNESP, Araraquara, São Paulo, Brazil.

\section{Collaborators}

FS SALMEN, surgical procedure and the documentation of the cases. MR OLIVEIRA, collect of data; literature review, writing and submission of the manuscript. MAC GABRIELLI: statistical analisys and assisted in the preparation of the manuscript. ACG PIVETA, assisted in the surgical procedures and of the documentation of the cases. VA PEREIRA FILHO, assisted in collect of data and statistical analisys. MFR GABRIELLI, critical review of the writing of the manuscript and of the English version. 


\section{REFERENCES}

1. Eklund SA, Pittman JL. Third-molar removal patterns in an insured population. J Am Dent Assoc. 2001;132(4):469-475. doi: 10.14219/jada.archive.2001.0209

2. Ventã I. How often asymptomatic disease-free third molar need to be removed? J Oral Maxillofac Surg. 2012;70(1):4147. doi: 10.1016/j.joms.2012.04.037

3. Kunkel M, Kleis W, Morbach T, Wagner W. Severe third molar complications including death-lessons from 100 cases requiring hospitalization. J Oral Maxillofac Surg. 2007 Sep;65(9):1700-6. doi: 10.14219/jada.archive.2001.0209

4. Cunha-Cruz J, Rothen $M$, Spiekerman C, Drangsholt $M$, McClellan L, Huang GJ, et al. Recommendations for third molar removal: a practice-based cohort study. Am J Public Health. 2014 Apr;104(4):735-43. doi: 10.2105/AJPH.2013.301652

5. Kruger E, Thomson W, Konthasinghe P. Third molar outcomes from age 18 to 26: Findings from a population-based New Zealand longitudinal study. Oral Surg Oral Med Oral Pathol Oral Radiol Endod. 2001;92(2):150-155. doi: 10.1067/ moe.2001.115461

6. Freudlsperger C, Deiss T, Bodem J, Engel M, Hoffmann J. Influence of lower third molar anatomic position on postoperative inflammatory complications. J Oral Maxillofac Surg. 2012 Jun;70(6):1280-5.

7. Gbotolorum OM, Arotiba GT, Ladeinde AL. Assessment of factors associated with surgical difficulty in impacted mandibular third molar extraction. J Oral Maxillofac Surg. 2007;65(10):1977-83. doi: 10.1016/j.joms.2006.11.030

8. Pell G, Gregory B. Impacted mandibular third molars: Classification and modified techniques for removal. Dent Dig. 1933;39:330-8.

9. Akadiri OA, Obiechina AE. Assessment of difficult in third molar surgery: a systematic review. J Oral Maxillofac Surg. 2009;67(4):771-4. doi: 10.1016/j.joms.2008.08.010

10. 3Winter GB. Principles of exodontia as applied to the impacted third molar. St Louis: American Medical Books; 1926.

11. Morales-Trejo B, Rocha-Navarro ML, Acosta-Veloz AL, JuarezHernández A. Class, type and position of 9148 surgically removed third molars in 3206 patients; A retrospective study. Med Oral Patol Oral Cir Bucal. 2012;17(3):e447-e451. doi: 10.4317/medoral.17548

12. Santos TS, Santos JASS, Martisn-Filho PRS, Silva LC, Silva EDO, Gomes AC. Prediction of postoperative facial swelling pain and trimus following third molar surgery based on preoperative variables. Med Oral Patol Oral Cir Bucal. 2013;18(1):e65-e70. doi:10.4317/medoral.18039

13. Hupp JR, Ellis E, Tucker MR. Contemporary oral maxillofacial surgery. 6th ed. St. Louis: Elsevier; 2014.
14. Figueiredo R, Valmaseda-Castellón E, Berini-Aytés L, GayEscoda C. Delayed-onset infections after lower third molar extraction: a case-control study. J Oral Maxillofac Surg. 2007;65(1):97-102. doi: 10.1016/j.joms.2005.10.063

15. Bui $\mathrm{CH}$, Seldin EB, Dodson TB. Types, frequencies and risk factors for complications after third molar extraction. J Oral Maxillofac Surg. 2003;61(12):1379-1389. doi: 10.1016/j. joms.2003.04.001

16. Arteagoitia I, Diez A, Barbier L, Santamaría G, Santamaría J. Efficacy of amoxicillin/clavulanic acid in preventing infections and inflammatory complications following impacted mandibular third molar extraction. Oral Surg Oral Med Oral Pathol Oral Radiol Endod. 2005;100(1):E11-E18. doi: 10.1016/j.tripleo.2005.03.025

17. Pogrel MA. What Is the effect of timing of removal on the incidence and severity of complications? J Oral Maxillofac Surg. 2012;70(1):37-40. doi: 10.1016/j.joms.2012.04.028

18. Chuang SK, Perrot DH, Susarla SM, Dodson TB. Age as risk factor for third molar surgery complications? J Oral Maxillofac Surg. 2007;65(9):1685-92. doi: 10.1016/j.joms.2007.04.019

19. Haug RH, Perrot DH, Gonzalez ML, Talwar RM. The American Association of Oral and Maxillofacial surgeons age-related third molar study. J Oral Maxillofac Surg. 2005;63(8):11061114. doi: 10.1016/j.joms.2005.04.022

20. Bruce RA, Frederickson GC, Small GS. Age of patients and morbidity associated with mandibular third molar surgery. J Am Dent Assoc. 1980;101(2):240-5. doi: 10.14219/jada. archive.1980.0183

21. Ren YF, Malmstrom HS. Effectiveness of antibiotic prophylaxis in third molar surgery: a meta-analysis of randomized controlled clinical trials. J Oral Maxillofac Surg 2007;65(10):1909-1921. doi: 10.1016/j.joms.2007.03.004

22. Poeschl PW, Eckel D, Peschl E. Postoperative prophylactic antibiotic treatment in third molar surgery: a necessity? J Oral Maxillofac Surg. 2004;62(1):3-8. doi: 10.1016/j. joms.2003.05.004

23. Chuang SK, Perrot DH, Susarla SM, Dodson TB. Risk factors for inflammatory complications following third molar surgery in adults. J Oral Maxillofac Surg. 2008;66(11):2213-8. doi: 10.1016/j.joms.2008.06.067

24. Huang GJ, Cunha-Cruz J, Rothen M, Spiekerman C, Drangsholt $\mathrm{M}$, Anderson $\mathrm{L}$, et al. A prospective study of clinical outcomes related to third molar removal or retention. Am J Public Health. 2014;104(4):728-34. doi: 10.2105/AJPH.2013.301649

Received on: 13/3/2016

Final version resubmitted on: 2/4/2016 Approved on: 14/6/2016 